\title{
Introversión pedagógica sobre la educación militar
}

https://doi.org/10.21830/9789585380271.01

\author{
Martha Hortensia Arana Ercilla ${ }^{1}$ \\ Vicente Hernán Ibarra Argoty \\ Escuela Militar de Cadetes "General José María Córdova”
}

\section{Introducción}

Este capítulo es un preámbulo acerca del porqué esta investigación y sus resultados. Presenta el punto de vista de los investigadores sobre aspectos de la educación y la pedagogía que son polémicos en la actualidad, lo cual no significa que su perspectiva sea la única posible, sino que constituye un camino para proponer nuevas ideas en este campo del conocimiento desde el continuum histórico, la reflexividad pedagógica, la práctica educativa y los contextos. Los diferentes puntos de vista que se debaten sobre la pedagogía parten de diversos enfoques epistemológicos de la ciencia, así como de las concepciones sobre la vida y el ser humano. Además, se considera sustancial que, desde la diferencia, se produzcan encuentros y confluencias que posibiliten hallar ideas compartidas y mejores prácticas educativas.

También se debe destacar que si bien los análisis que se hacen en este libro se fundamentan en algunos autores, con esto no se pretende invocar el principio de autoridad, que como bien se sabe no se admite en ciencia, entre otras cosas porque suele haber varias autoridades en bandos opuestos. Antes bien, el propósito es mostrar desde la literatura disponible la compatibilidad de las ideas que permiten a los autores justificar sus puntos de vista, opiniones y reflexiones, para lo cual se cita a investigadores y educadores con quienes se

$1 \mathrm{PhD}$ en Educación de la Universidad Tecnológica de La Habana y posdoctorado en Educación de la Universidad Pedagógica de Colombia. Economista de la Universidad de La Habana. Docente investigadora de la Facultad de Ciencias Militares de la Escuela Militar de Cadetes "General José María Córdova”.

2 Oficial de la Reserva Activa del Ejército Nacional de Colombia. Profesional en Ciencias Militares de la Escuela Militar de Cadetes "General José María Córdova". Magíster en Análisis y Prevención del Terrorismo de la Universidad Rey Juan Carlos, España. Abogado de la Universidad La Gran Colombia. Docente investigador de la Facultad de Ciencias Militares de la Escuela Militar de Cadetes "General José María Córdova”. 
comparten preocupaciones y soluciones. Esto no quiere decir que "tengan la razón", sino que "su opinión merece más consideración".

Aparte de lo anterior, también es necesario precisar que los investigadores que escribieron este libro comprenden el vínculo entre la educación, la pedagogía y la didáctica como una relación compleja y dialéctica que reconoce la unidad y la diferencia entre estos sistemas de conocimientos. Específicamente, consideran que esta interconexión significa que cada una de estas áreas no puede existir al margen de la relación y que sus especificidades se expresan en lo que cada una aporta al conjunto. Asimismo, entienden que el desarrollo de la educación, la pedagogía y la didáctica está determinado por las épocas, los contextos específicos y los avances de la cultura y la sociedad, de ahí que pueden cambiar sus contenidos y la propia relación entre ellas.

Hoy se producen numerosos cambios en la sociedad y la cultura debido al desarrollo de nuevos conocimientos científicos, los cuales no solo impactan las concepciones sobre la vida, el planeta, el universo y, en consecuencia, la naturaleza del ser humano y su construcción histórica, sino también fundamentalmente la comprensión de los seres humanos sobre lo que somos y debemos ser, en la conciencia de la necesidad de cambio. Precisamente, la educación es uno de los ambientes sociales y culturales desde los cuales se transforma el pensar, el sentir y el actuar. Por esta razón se hace imprescindible enriquecer estos conocimientos y saberes experienciales desde las nuevas ciencias de la vida y de la sociedad, pero no solo por lo que se ha expresado hasta este punto, sino sobre todo porque permanecen contradictoria y paralelamente el incremento de la intolerancia, la pobreza, la dominación, la diferenciación, la violencia, la drogadicción, entre otros males sociales, que para la mayoría de las personas tienen sus causas en las carencias de la educación.

Sin embargo, cuando se hace referencia a la llamada crisis de la educación se obvia lo anterior y solamente se menciona la evaluación de los procesos, los aprendizajes, los diseños curriculares, la formación de los educadores, la actualización e integración de las disciplinas científicas, la política educativa, entre otros. Por supuesto, estos aspectos no son menos importantes, pero es necesario relacionarlos con los macroproblemas educativos, ya que todos pasan por la reflexión y el análisis de entender ¿qué es la educación?, ¿qué ha sido y qué puede llegar a ser?, ¿qué papel tiene en las transformaciones sociales y cultu- 
rales?, ¿cómo, a su vez, estas influyen en su avance y progreso? y, sobre todo, ¿en qué consiste educar? Asimismo, hay que reconocer y solucionar tres problemas históricos centrales para resolver estas preocupaciones: ¿Cómo lograr una educación comprometida con el ser humano?, ¿cómo superar dialécticamente los modelos estrechos, instrumentales, reduccionistas, disciplinarios y reproductivos? Por último, ¿cómo actualizar la cultura de las instituciones educativas poniendo en el centro al conocimiento y las emociones del ser humano, en la construcción de comunidad académica?

La producción de saberes y, consecuentemente, la creación de nuevos campos del conocimiento exigen revaluar los problemas de la educación en un sentido amplio, desde lo social-cultural y teniendo en cuenta los procesos de enseñanza-aprendizaje, de tal manera que surja un diálogo de sentidos desde los derechos y deberes humanos en la educación y sus diferentes niveles, los cuales se deben concretar en el modelo pedagógico, la práctica educativa y la gestión de las instituciones. Así es posible dar un lugar central a las personas y formular una didáctica adecuada para abordar contenidos que respondan a la ciencia, la tecnología, la realidad social, la naturaleza humana y la vida. En consecuencia, en este escenario es imprescindible potenciar al sujeto en su aprendizaje, de modo que pueda dirigir su propio desarrollo, pues, precisamente, en ello consiste la interacción entre la educación y los procesos pedagógicos y didácticos.

Como parte de este ejercicio reflexivo hay que acudir a la historia de la educación y a las diferentes ideas pedagógicas propuestas por educadores y otros profesionales que han permitido que hoy contemos con un acercamiento a esta. Entre ellos se debe mencionar a Platón, Aristóteles, Rousseau, Dewey, Erasmo, Vives y Moro, quienes, a partir de concepciones epistemológicas y vivencias históricas concretas, han concebido la educación como una actividad humana y social.

\section{Educación, cultura y sociedad}

Hoy, pensar la educación exige comprender la naturaleza humana bio-psico-social, compuesta por la psiquis y la herencia genética de las personas, mediatizadas por los factores socio-históricos en que se desarrollan. El ser 
humano que la educación debe plasmar es el dado por la naturaleza, al cual tiene que integrar los requerimientos sociales. No obstante, ya que la escala de valores cambia con las sociedades, esta jerarquía y los contenidos no permanecen iguales a lo largo de la historia. Ayer se alababa la valentía, hoy en día es el conocimiento; mañana quizá será la sensibilidad hacia la vida. Tanto en el presente como en el pasado, nuestro ideal educativo es obra de la sociedad. En este sentido, se puede afirmar que la educación es el proceso social de interacción humana que conduce al avance social, que tiene como misión mantener, preservar y desarrollar la cultura humana, en su contexto histórico y específico. De ahí que la comprensión de la relación cultura-educación-sociedad sea esencial para dicha función social.

Luego, la cultura es resultado de la creación humana, es la esencia que nos diferencia e identifica; la sociedad es el medio y la organización en que esta se desarrolla, y la educación es el proceso de influencias sociales y culturales intencionado que permite el desarrollo individual de la persona, de los grupos sociales y de la sociedad en su conjunto. La cultura es, por tanto, la creación espiritual y material de la humanidad, es a la vez el contenido y la fuente de la educación, del mismo modo que a través del proceso social educativo se logra el avance, el desarrollo, la socialización, el mantenimiento y la permanencia de la creación humana en toda su diversidad, es decir, de la cultura. La educación recibe y ofrece conocimientos que son parte integrante de la cultura, por cuanto es el proceso de influencias que ejerce la sociedad, la familia, la escuela, los medios de comunicación y las instituciones sociales en las personas y grupos.

A partir de aquí es posible identificar la dialéctica de la educación como un proceso social y cultural. Por una parte, es conservadora, puesto que mantiene lo que se considera valedero de la cultura en el tiempo; y, por otra, es liberadora y transformadora, gracias a los nuevos conocimientos y relaciones humanas que produce. Es por medio de esta tensión que se producen los avances y los estancamientos en la educación. En resumen, la educación es un proceso de concienciación social en constante evolución, sobre el cual inciden múltiples factores del acervo cultural espiritual y material de la humanidad, que determinan el ser, el pensar y el actuar en la sociedad. 


\section{Las ciencias de la educación}

El objeto de la educación se puede identificar desde disímiles puntos de vista: la pedagogía, el saber pedagógico, la ciencia de la educación o las ciencias de la educación. En la actualidad, las denominadas ciencias de la vida permiten integrar el conocimiento de diferentes ciencias, gracias al desarrollo de la biología molecular, la neurobiológica, la genética y los estudios del cerebro, que se caracterizan por su intervencionismo, emergencia y continuidad. Estas ciencias explicativas pasaron a ser ciencias activas en la transformación de la vida a través de la medicina, la antropología, la sociología, la política, etc., con lo cual contribuyeron al desarrollo de conceptos y métodos, así como de nuevos campos científicos, entre ellos la neuroeducación y la informática educativa, las cuales ampliaron la profesión de educar.

Así, las ciencias de la educación, surgidas en el siglo XX, son resultado del desarrollo científico y su aplicación al campo de la educación. Específicamente, constituyen un conjunto de disciplinas que comienzan a ser necesarias para el proceso de enseñanza y aprendizaje. Biólogos, etólogos, psicólogos, antropólogos, sociólogos, filósofos, físicos, químicos, matemáticos, fisiólogos, neurólogos, decenas de científicos ${ }^{3}$ y diversas asociaciones científicas propugnan por la unidad de la ciencia - lo que el sociobiólogo E. Willson denomina consilience-, como unidad del conocimiento, para comprender la naturaleza de la vida, de los seres humanos y del cosmos, así como para que las personas tomemos conciencia sobre quiénes somos, de dónde venimos y para dónde vamos, por medio de la maravillosa aventura del conocimiento, que tanto requiere la educación.

Desde el punto de vista histórico, las llamadas ciencias de la educación son una evidencia de que los nuevos conocimientos permiten abordar la enseñanza y el aprendizaje desde una dimensión más amplia, como ha sucedido a lo largo de su desarrollo. En este sentido, un proceso complejo como la educación no puede ser objeto de estudio exclusivo de un campo del saber ni

3 Entre los cuales cabe mencionar a Jesús Mosterín, Peter Medawar, Edward O. Wilson, Martin Gardner, Konrad Lorenz, Robert Ardrey, Francisco José Ayala, J. Díaz, L. Ruiz, Manuel Toharia, Theodosius Dobzhandsky, Ernst Mayr, George Gaylord Simpson y Francisco Mora Taruel. 
un único campo puede sintetizarlo; por el contrario, la riqueza de las distintas perspectivas que lo constituyen enriquece otros sistemas de conocimientos, como la pedagogía.

\section{Pedagogía y didáctica}

Para muchos, la pedagogía ha sido relegada a un conocimiento de carácter instrumental, denominada didáctica. Desde Comenio hasta el presente, la didáctica es el saber pedagógico que propone y reflexiona sobre los métodos y las estrategias metodológicas del proceso de enseñanza-aprendizaje. Uno de los ejemplos se halla en la metodología y material didáctico que desarrollaron María Montessori y Ovide Decroly, que constituye una de las propuestas que marcan la llamada pedagogía moderna, es decir, la pedagogía activa. Sus bases fundamentales están en los principios de la biología y la psicología, trasladados a la pedagogía y enriquecidos desde allí. Al decir de Alberto Merani, "ellos no parten de principios ni se afincan en declaraciones grandilocuentes y abstractas, sino que arrancan del real concreto que es el nińo y la circunstancia en que vive, para poder llagar al hombre y sus circunstancias futuras" (Merani, 1977, p. 70).

Entonces, la didáctica es una rama del saber pedagógico que estudia el proceso educativo y formativo desde la enseñanza-aprendizaje. Este saber pedagógico, que busca comprender, explicar y modelar de qué manera se debe llevar a cabo el proceso educativo, ha tenido su mayor desarrollo a partir de los años setenta hasta la actualidad. Con el aporte de disciplinas específicas, como la matemática, la física, la lingüística, etc., la didáctica avanza a través de diferentes escuelas, entre ellas la de Célestin Freinet en Francia, la cual hace énfasis en la enseñanza, y otras vinculadas a la psicología del aprendizaje a partir de Jean Piaget, que estudian el proceso de formación de conocimientos. En ello consiste parte de su polémica y a la vez de su riqueza.

Ahora bien, la didáctica también se debe adaptar a los cambios antes mencionados. Por una parte, la complejidad y el incremento del conocimiento en forma exponencial afecta sus componentes y sus relaciones, y, por otra, el carácter interdisciplinar incide no solo en los contenidos, sino también en los métodos y las formas de la enseñanza y el aprendizaje. Del mismo modo, 
nuevas concepciones educativas priorizan otras partes de los contenidos, como son los valores y las actitudes para lograr la formación integral.

En este contexto, cada día es más necesario interpretar la correlación que existe entre conocer cómo aprende un estudiante y saber qué hacer para ayudarlo a aprender mejor, como proceso activo, creativo y propio del sujeto que aprende. Así, la capacidad de resolver problemas, de adaptarse a nuevas situaciones, de seleccionar la información, de tomar decisiones, de seguir aprendiendo y de interconectar los conocimientos de las diversas disciplinas, así como de usar la tecnología de la información y las comunicaciones, etc., constituyen estrategias didácticas acordes con los cambios del mundo actual.

Luego de esta breve reflexión, se puede resumir que existe una relación dialéctica entre la educación, la pedagogía y la didáctica, que se sintetiza en que la educación es el proceso de formación social a partir de la cultura; la pedagogía es el sistema estructurado de conocimientos que permite reflexionar sobre la enseñanza y el aprendizaje, al tiempo que genera ideas y modelos para la educación en la sociedad, es decir, extiende la cultura; y, finalmente, la didáctica es la rama del conocimiento pedagógico que estudia la práctica educativa, es decir, lleva a cabo el proceso de enseñar para aprender. En ello radica su unidad y diferencia.

\section{Perspectivas sobre la pedagogía y la didáctica}

En cada etapa de la historia, los estudiosos de la educación han aceptado firmemente ideas pedagógicas como verdaderas, de modo que se han convertido en mitos y paradigmas difíciles de cambiar en la práctica educativa. En contraste, comprender la dialéctica entre la educación, la pedagogía y la didáctica permite que las "verdades absolutas" sean interrogadas, contextualizadas, reflexionadas, transformadas e innovadas, para proponer otras desde los nuevos conocimientos. Es en ese movimiento de cambio permanente que se desarrolla la educación.

Precisamente, entre las razones que permiten pensar la pedagogía de modos diferentes y hasta contradictorios está la comprensión epistémica sobre el conocimiento, la ciencia y las ciencias sociales, respecto a las relaciones que 
se establecen entre la racionalidad y la emocionalidad; lo teórico y lo experiencial, entre otras. En posiciones extremas de aislamiento, estos factores inducen a que la diferencia se tome como exclusión, y no lo común y la unidad que existe entre ellos, lo cual impide reconocer sus conexiones y vínculos, entendidos no como las diferencias, sino lo común, la continuidad y la unidad histórico-genética.

Como resultado se originan diferentes posicionamientos y debates acerca de si la pedagogía es un saber experiencial, una práctica, una ciencia o una metodología, de manera que los esfuerzos se dispersan en destacar los elementos de oposición, y no en analizar la lógica del proceso de desarrollo genético e histórico que ha marcado a este conocimiento en la evolución de la educación. Del mismo modo ocurre cuando, al pensar la pedagogía, se aíslan sus ideas, corrientes y modelos — los cuales han surgido en diferentes momentos históricos y sociales_, al tiempo que se enfrenta lo "viejo" con lo "nuevo". Este es el caso, por ejemplo, del rechazo a la pedagogía tradicional y al conductismo pedagógico que se observa hoy en algunas propuestas, las cuales, por su declaración "humanista", parecerían ser novedosas e ideales, como sucede en el constructivismo pedagógico y sus variantes. Este rechazo se produce sin que haya una reflexión crítica sobre las relaciones y el continuum que hay entre estas ideas y sus propuestas, ni tampoco sobre el contexto real de formación en que se desean aplicar ni lo que piensan y pueden aplicar los sujetos del proceso educativo.

Como complemento a lo anterior, se reconoce que

la educación es pues un fenómeno que puede asumir las formas y las modalidades más diversas, según sean los diversos grupos humanos y su correspondiente grado de desarrollo; pero, en esencia, es siempre la misma cosa, esto es, la transmisión de la cultura del grupo de una generación a la otra, merced a lo cual las nuevas generaciones adquieren la habilidad necesaria para manejar las técnicas que condicionan la supervivencia del grupo. Desde este punto de vista, la educación se llama educación cultural en cuanto es precisamente trasmisión de la cultura del grupo, o bien educación institucional, en cuanto tiene como fin llevar las nuevas generaciones al nivel de las instituciones, o sea, de los modos de vida o las técnicas propias del grupo. (Abbagnano \& Visalberghi, 1964 , p. 6) 
Por supuesto, esto no significa que en la historia de la educación y su realidad actual no haya renovación e innovaciones a través de nuevas ideas y prácticas pedagógicas, ceñidas a las condiciones existentes de cada época. Es decir, la educación es el vehículo que, a través de los conocimientos pedagógicos, permite el desarrollo cultural de los seres humanos; a su vez, la cultura es el contenido de la educación en la sociedad y simultáneamente su resultado. Por lo tanto, como se ha afirmado, la educación conserva y renueva la cultura. De ahí que la historia, la epistemología y las ideas pedagógicas estén íntimamente vinculadas para poder comprender los problemas actuales de la educación.

Precisamente, lo que se ha expuesto constituye un camino metodológico para reflexionar acerca de las limitaciones que existen actualmente en la educación, las cuales son el resultado de diversos factores, entre los cuales se pueden mencionar los siguientes: las limitaciones del pensamiento dialéctico, histórico y crítico; la falta de una mirada de continuidad, proceso y transdisciplinariedad que rompa posiciones cerradas; el desconocimiento de la historia de la educación y del lugar que tiene el contexto educativo.

La ausencia de la reflexividad epistémico-pedagógica, histórica y contextual en la educación y la pedagogía, sustituida por la inmediatez de lo instrumental, la subjetividad, el relativismo, la carencia de comunidades académicas sólidas y el oficialismo en las decisiones que buscan transferir propuestas de otros contextos son factores que conducen a debates estériles y al estancamiento de la educación. Estas posturas se sustentan fundamentalmente en cuatro tendencias: (1) "el todo vale, el todo es posible y esa es mi experiencia", (2) la falsa crítica a la ciencia y la carencia de una actitud científica e investigativa; (3) la búsqueda a ultranza de la innovación educativa y la aparente calidad normativa basada en los resultados, y (4) las posiciones posmodernistas que facilitan y contribuyen a la negación del estatuto científico, la historia y la filosofía a partir del rechazo al positivismo en las ciencias sociales, sin percatarse de que aquello que niegan es precisamente el componente esencial para comprender y hacer avanzar la pedagogía y la educación.

$\mathrm{Al}$ respecto, De Counti (2018) afirma que para corregir estas posturas se requiere la reflexión pedagógica y la verdad pluralista, capaz de unificar los dife- 
rentes enfoques de conocimiento pedagógico. Además, propone la concepción tripartita del conocimiento, para pensar la pedagogía desde lo proposicional, verdadero y pluralista, y señala que así el enfoque positivista es solamente un modo particular de conocimiento pedagógico, sin la pretensión de excluir a otros modos de conocimiento. De esta manera, la investigación pedagógica no sería una empresa con paradigmas en competencia por el campo de la verdad, sino que sería una tarea con múltiples métodos de investigación complementarios y que debería integrarse para promover una comprensión lo más completa posible de la dimensión educativa y formativa.

Cabe señalar que esta reflexión plural de comprensiones a la que hace referencia De Counti (2018) solo es posible cuando existe un sólido conocimiento de la epistemología y la historia de la pedagogía y la educación, un requisito que también se exige en todas las disciplinas. Únicamente así se puede llevar a cabo un verdadero ejercicio consciente de la profesión de educar, abandonando la neutralidad contextual, y asumir una posición determinada.

\section{El modelo pedagógico de la formación militar}

Como es sabido, diseñar y aplicar una propuesta pedagógica o un microcurrículo es una preocupación para muchos educadores e investigadores de la educación, pues definir el enfoque, las estrategias, los métodos, las formas y los medios de enseńanza y aprendizaje exige del conocimiento de la epistemología y la historia de la educación, de las tendencias actuales, de las particularidades de la formación y sus tradiciones, así como de los contextos específicos en que se aplicaría, de lo cual deben estar conscientes los educadores.

Precisamente, este libro expone los resultados de una investigación sobre las particularidades del modelo pedagógico en la educación militar, en la cual se adoptó un enfoque epistémico e histórico-genético para analizar el continuum de las ideas pedagógicas que fundamentan la relación entre el conductismo y el constructivismo en esta formación profesional. Con este propósito, el texto responde, entre otros, a los siguientes interrogantes: ¿Cuál es la contribución de las ideas pedagógicas desarrolladas en el siglo XX a la educación actual? ¿Qué aportan las ideas pedagógicas del siglo XX al análisis valorativo de 
los problemas pedagógicos presentes? ¿Cómo se incorporan los nuevos conocimientos sobre el ser humano y su cognición a la pedagogía actual, desde la mirada de lo ocurrido en el siglo XX? ¿Qué se tiene en cuenta de la pedagogía y su historia para pensar y proponer cambios a la educación?

A partir de estas preguntas, se han pensado, construido y aplicado las propuestas pedagógicas, los fundamentos y rasgos del modelo pedagógico que rige actualmente la formación integral de los profesionales en ciencias militares en Colombia, la cual ha sido desde hace algunos años una preocupación y ocupación constante de la investigación educativa en la Escuela Militar de Cadetes "General José María Córdova” (EsMic). Este modelo pedagógico, que se considera mixto por las particularidades del contexto de la formación militar, ha sido recogido en los documentos rectores oficiales y los principios doctrinales que rigen la educación de este profesional para sus actuaciones futuras, desde donde se elaboraron sus fundamentos epistémicos, axiológicos, antropológicos y pedagógicos.

Específicamente, el componente pedagógico se ha formulado con la autenticidad necesaria, pero también asumiendo los planteamientos de los documentos rectores, en los cuales se reconoce el currículo basado en la formación por competencias. De aquí deviene la idea de que estas pueden ser el núcleo que unifique las características pedagógicas del conductismo y el constructivismo, pues, sin duda, hay competencias que se desarrollan en el establecimiento y cumplimiento de la norma, la orden, el mando, el respeto a la jerarquía y la disciplina, para mencionar algunas de las conductas que se esperan del estudiante en formación y del profesional en la estructura, equipo, pelotón o compañía a la que pertenezca.

No obstante, al mismo tiempo, la propuesta pedagógica busca que dichas competencias se nutran de la autonomía y la creatividad, las cuales permiten un aprendizaje independiente y en equipo, la toma de decisiones individuales y colectivas, la investigación, entre otros rasgos, lo que en la formación se denomina un liderazgo en sí mismo. En este sentido, se trata de relacionar lo normativo y obligatorio con lo reflexivo y consecuente que conforma el carácter en este profesional, de manera que los valores vayan escalando niveles de desarrollo, hasta llegar a su apropiación y educabilidad consciente, como parte intrínseca de su comportamiento y ética profesional. 


\section{Carácter dual, complementario y mixto del modelo pedagógico}

Como se esbozó al principio, muchas personas sostienen que el diálogo formativo entre estos dos caminos pedagógicos en relación es imposible, pues consideran que son dos enfoques opuestos. Esta posición empeora aún más cuando rechazan el conductismo porque lo comprenden en el marco estrecho de la inmovilidad del pensamiento y la acción independiente del estudiante, implícito solo en la subordinación al profesor y el adoctrinamiento de ideas y acciones conducidas.

Por el contrario, el modelo pedagógico formulado reconoce y afirma que la formación propiamente militar, basada en la norma, la disciplina, la jerarquía y el mando desde la instrucción de conocimientos y comportamientos, no solo tiene características del conductismo, sino que también está fundamentada en elementos constructivistas de una pedagogía actual, basada en el pensamiento crítico, creativo, de cultura general y valores éticos, estéticos, entre otros, los cuales son el resultado de un proceso de aprendizaje autónomo e independiente para la formación integral.

Es decir, esta propuesta argumenta que hay una relación genética y epistémica entre el conductismo y el constructivismo pedagógicos que forma un continuum pedagógico, de tal manera que se excluye el eclecticismo acrítico y el holismo totalizador. No obstante, para algunos de los que hemos participado en la elaboración del modelo pedagógico institucional, siempre ha quedado la inquietud de que esa dualidad y mixtura presente en el contexto educativo militar no ha sido suficientemente argumentada desde la pedagogía y la educación.

Precisamente, en respuesta a esta situación, el libro se centra en fundamentar pedagógicamente el carácter dual, complementario y mixto del modelo pedagógico militar, respecto a la relación entre los dos enfoques aparentemente en oposición: el conductismo y el constructivismo pedagógicos. Respecto a los alcances de la propuesta cabe anotar que si bien esta investigación explora los fundamentos epistémicos que conforman el modelo educativo en la EsMic, sus resultados no se restringen a esta institución, sino que podrían ser sostén de todo modelo pedagógico en la formación militar, o al menos puede delinear un camino para la investigación y el diálogo pedagógico necesario en otras instituciones. 
En concordancia con lo anterior, la pregunta de investigación fue la siguiente: ¿Qué fundamento epistémico-pedagógico sustenta la relación entre el conductismo y el constructivismo en este modelo educativo? Para responderla, se parte del supuesto de que el eclecticismo crítico, la reflexividad pedagógica (rasgos del giro epistémico en las ciencias sociales actuales) y el continuum del conocimiento en la historia de la educación permiten argumentar la relación entre el conductismo y constructivismo en aspectos comunes que integran el modelo educativo de la formación militar integral estudiado. De esta manera, se rompe la formalidad de los planteamientos teóricos establecidos y se consolida una propuesta educativa auténtica y propia desde el contexto militar colombiano (Perilla, 2018; Posner, 2005; Vera \& Palma, 2017).

Así, por una parte, la investigación se fundamenta en la epistemología e historia de la pedagogía para argumentar las conexiones e identidades que tienen las ideas pedagógicas estudiadas, y, por otra, tiene como principio construir nuevo conocimiento mediante la investigación educativa y los aportes de los nuevos saberes científicos, lo que Bedoya (2018) llama una "nueva actitud epistemológica de cambio" (p. 110). Al respecto, este autor reivindica al educador e investigador reflexivo en razón al contexto, a la epistemología y la historia de la pedagogía: "Solo así se pueden hacer propuestas de cambios que funcionen [...]. No es el modelo lo determinante, sino la actitud que a lo largo de la historia ha permitido generar ideas nuevas, basadas en lo existente" (Bedoya, 2018, pp. 117-122). Es decir, se puede afirmar que es el modelo pensado y construido desde allí.

La reflexión crítica asentada en la unidad del conocimiento pedagógico y su evolución histórica — no simplemente desde lo disciplinar— desentraña la conexión, coexistencia y compatibilidad entre diferentes ideas pedagógicas de contextos históricos y particulares, como entre el conductismo y el constructivismo pedagógicos. En este sentido, la propuesta se inscribe en el debate epistemológico y pedagógico contemporáneo, que analiza críticamente las ideas y los enfoques que han estado vigentes en la pedagogía desde el siglo XX hasta la actualidad.

Asimismo, la investigación parte del principio de que todo lo que somos, sabemos y tenemos hoy está construido sobre los legados de nuestros antepa- 
sados, de sus ideas y la sabiduría colectiva de la humanidad. Por ser la única especie que crea algo nuevo por tener una historia; por caminar en el tiempo sobre los hombros de las generaciones que nos antecedieron, y porque nos hemos comunicado a través del lenguaje, el arte, la música y, hoy, los códigos tecnológicos que nos permiten conocer y utilizar los primeros modelos de la enseñanza y el aprendizaje humanos, a los cuales debemos acudir. Esta perspectiva ha orientado la preocupación de los autores respecto a la separación entre la docencia y la investigación pedagógica para producir los cambios en los procesos educativos a todos los niveles, entiéndase las transformaciones curriculares, la evaluación, la didáctica y la gestión educativa. Al respecto, Arana (2018) destaca:

Hoy se habla del profesor investigador como algo novedoso, como una nueva característica del educador, pero en realidad esto significa que se ha olvidado qué es enseńar y educar, así como lo que el maestro ha sido a través de la historia.

[...].

En consonancia, cada vez se hace más necesaria la reflexión epistemológica, metodológica y axiológica de las ciencias en la educación para solucionar los problemas actuales desde maneras de pensar, actuar y generar cultura.

[...].

La respuesta se encuentra en múltiples factores: comprender al ser humano desde la unidad e integridad de los procesos emocionales y cognitivos, por una parte, e intuitivos y científicos, por otra [...]. Construir una imagen real y actual de la ciencia y la tecnología en relación con la sociedad, criticar las concepciones estandarizadas y reduccionistas de esta; reforzar la posición de la unidad del conocimiento; fomentar una pedagogía que se centre en quien aprende. (pp. 37-68)

A pesar de los avances en la comprensión sobre el ser humano y su proceso cognitivo, así como de los nuevos conocimientos incorporados, las ideas, enfoques y paradigmas pedagógicos tienen limitaciones para responder a las exigencias de la formación en las nuevas generaciones. En este sentido, para Bedoya (2018),

hay que proponer, pues, una investigación acerca de lo pedagógico en este sentido, es decir, desarrollar un estudio crítico: epistemológico e histórico, 
que tenga como objetivo descubrir y demostrar cómo lo pedagógico ha estado presente en el sistema educativo desde el momento mismo en que este se institucionaliza en la modernidad. (p. 100)

Asimismo, se debe considerar que la pedagogía se halla en continuo proceso de reelaboración y reconstrucción, ya que al ser un sistema de conocimientos, no está completamente definida ni delimitada teórica ni epistemológicamente. Esta característica de la pedagogía limita la orientación lógica y rigurosa de los modelos educativos y, en particular, de las instituciones educativas y sus programas, los cuales dependen de los contextos. Como consecuencia, las ideas pedagógicas se encuentran dispersas, en ocasiones no hay continuidad en su desarrollo y no se reconocen unas en otras.

Por esta razón las personas renuncian a la investigación teórica y se concentran en la llamada innovación educativa, en los diseños curriculares o en las estrategias pedagógicas de enseñanza y aprendizaje. Esta decisión los lleva a elegir un modelo reconocido y asumir una de sus posiciones, mas no profundizan en los sistemas epistémicos que están presentes ni evalúan si estos les permiten construir un modelo pedagógico ideal, pero a la vez real, que corresponda a las intencionalidades educativas, los contextos y las experiencias de cada ambiente de la cultura institucional.

En contraste con esta posición, para la Esmic el modelo pedagógico debe expresar el ideal de formación de la profesión militar — partiendo de la historia de esta formación - y las exigencias educativas actuales, de acuerdo con los cambios de las ciencias y la profesión militar. Consecuentemente, definir el modelo pedagógico exige reflexionar sobre la profesión militar.

El modelo que se precisa, entonces, se debe fundamentar en las pedagogías contemporáneas y en tensión con la pedagogía tradicionalista, disciplinar, enfocada en el que enseña. Antes bien, se precisa un modelo que se centre, entre otros, en estos aspectos:

- La intencionalidad de la educación.

- $\quad$ El sujeto que aprende, es decir, en la correspondencia entre lo cognitivo y lo emocional.

- Las relaciones interpersonales basadas en la colaboración, el trabajo en equipo, los valores y los ambientes educativos. 
- Las nuevas tecnologías como herramientas.

- La ciencia y la investigación.

Simultáneamente, este modelo debe conservar características esenciales del perfil profesional, que en su relación con los aspectos anteriores adquieren un nuevo significado y sentido en la educación militar:

- La disciplina.

- La organización.

- La norma.

- $\quad$ El mando.

Así, el modelo pedagógico se construye en la articulación entre el saber, el saber hacer, el ser y el convivir; el enseñar y el aprender; entre la norma heterónoma y la autonomía del sentido y significado. Concretamente, el modelo pedagógico ideal consiste en una construcción mixta e integradora de rasgos diversos y aparentemente opuestos, pero que se integran en una relación dialéctica. Entonces, ¿qué fundamenta epistémica y pedagógicamente el carácter híbrido y heterogéneo del modelo educativo militar?

\section{Antecedentes de la investigación}

Para mostrar las dimensiones del problema planteado, en este apartado se hace un recuento de los estudios que ha realizado la Esmic sobre esta materia y se resume la situación actual de la investigación sobre el modelo pedagógico en la formación militar. Además, con esto también se busca destacar las limitaciones que existen en la fundamentación epistémico-pedagógica y sus relaciones con el perfil de la formación. Entre los hallazgos que se obtuvieron al analizar los trabajos revisados se debe destacar la falta de reflexividad pedagógica de los contextos específicos, pues se observó que se toman modelos generales que no son transferidos ni adaptados al perfil profesional.

Asimismo, se encuentra que las propuestas analizadas plantean los fundamentos epistémico-pedagógicos de los modelos educativos desde el holismo y 
el constructivismo, pero no argumentan por qué lo hacen de esta manera. En lugar de esto, regularmente se refieren el holismo como la integración de las Fuerzas Militares y su misión en la sociedad, mientras que presentan el constructivismo simplemente como un ideal pedagógico para la formación integral del futuro profesional. En otros casos, si bien asumen rasgos de diferentes corrientes pedagógicas generales, no las relacionan a través de sistemas conceptuales que justifiquen esta integración, de modo que no logran construir un modelo pedagógico propio, sino simplemente una sumatoria de rasgos.

Este análisis evidencia que es necesario construir sólidos fundamentos epistémicos-pedagógicos con base en las ciencias militares y en los principios doctrinales y profesionales, de tal manera que permitan plantear un modelo pedagógico cercano al contexto militar. Con este propósito, a través de la ecuación de búsqueda: "Modelo pedagógico en la formación militar", se consultaron artículos científicos y documentos institucionales, así como aquellas investigaciones culminadas de la Esmic que han contribuido gradualmente a consolidar el diseño del modelo pedagógico de la Escuela. Estos estudios se presentan a continuación.

Como fase inicial se encuentra "El redimensionamiento curricular por competencias en la formación del profesional en ciencias militares", de Carlos Acosta Arévalo (2010). Este trabajo adecuó los lineamientos pedagógicos y curriculares a la construcción de la formación por competencias actuales y su diseño curricular, que está en permanente mejoramiento. Por su parte, "La evaluación de competencias transversales de lectoescritura en el área de investigación en la formación del profesional en ciencias militares" inició la reflexión de la dualidad y mixtura del modelo pedagógico que hoy se tiene. Específicamente, sus autores fueron Carlos Acosta Arévalo, Martha H. Arana Ercilla, Marcela Mendoza Gómez, Frank L. Valencia y José Alexander Muñoz (2011).

Posteriormente, se avanzó con la investigación “Estudio exploratorio-descriptivo del proceso de formación y desarrollo de las tutorías y los trabajos de grado, de quinto al octavo semestre en la Escuela Militar de Cadetes”. Este trabajo, que abarcó el período comprendido entre el 2016 y el 2018, analizó la relación entre la doctrina militar, el perfil profesional y el modelo pedagógico. En este caso, los investigadores fueron Martha H. Arana Ercilla, Vicente H. 
Ibarra Argoty, Carlos Acosta Arévalo y Daiana Reyes García. Todos estos resultados fueron publicados en diferentes libros.

A continuación se hace referencia a documentos de otras instituciones. En primer lugar está "El modelo pedagógico del sistema educativo de la Fuerza Aérea Colombiana” (2017), en el cual se señala:

Pensar en un modelo pedagógico para las escuelas y las unidades académicas de la FAC implica abordarlo desde el mismo paradigma formativo que tienen los actores educativos del contexto — regional y local— sobre la manera como los militares desarrollan sus prácticas pedagógicas en el ambiente de la formación, la capacitación, la instrucción y el entrenamiento.

[...].

En el marco del proyecto educativo institucional y a partir de los postulados que sobre la formación se plantearán, acudiremos a algunas concepciones que sobre modelos pedagógicos existen y se han desarrollado a nivel de instituciones educativas y formas de pensamiento, ya que a partir de ellas se ha configurado el modelo pedagógico holístico castrense aeronáutico, fundamento formativo de las unidades educativas de la Fuerza Aérea Colombiana. (pp. 6-7)

$\mathrm{Al}$ analizar este documento se evidencia, como se señaló anteriormente, la tendencia a asumir los modelos de manera general y buscar su posible adaptación y acomodo a la formación. Asimismo, se encuentra que la falta de un posicionamiento epistémico y pedagógico propio se justifica a través del enfoque holístico. En concreto, se afirma que la mayoría de los modelos se plantean como holísticos, pues la educación holista es considerada, a partir de la década de los noventa, como el nuevo paradigma educativo para el siglo XXI, el cual recupera el mejor conocimiento de diferentes campos y lo integra con los nuevos desarrollos de la ciencia de la totalidad. También se destaca que a través de esta mirada se percibe al mundo en términos de relación e integración, y se reconoce que toda la vida en la Tierra está organizada en una vasta red de interrelaciones, de manera que cuando los principios holísticos son aplicados a la educación, la escuela empieza a funcionar como un sistema vivo.

Además, no solo se destaca que el holismo tiene sus raíces en la proposición de que el universo es una totalidad integrada, en la cual todo está conectado, sino que además se señala que este corrige la falta de equilibrio de los 
métodos reduccionistas, pues enfatiza un concepto expandido de la ciencia y del potencial humano, de manera que además contiene implicaciones de gran significado para la ecología y la evolución humana. Esta afirmación sin argumentación epistémica hace que sea necesario estudiar a fondo la génesis del holismo, de tal forma que sea posible comprender las diferentes interpretaciones que existen desde la totalidad, sin que esto signifique descartar la dialéctica del todo y la parte, como se verá más adelante.

En segundo lugar se encuentra el artículo resultado de investigación de Neill Alfonso Medina (2017), "Pertinencia del Modelo Pedagógico Constructivista en los cursos de ascenso de Oficiales de la Armada Nacional y propuesta para su fortalecimiento”, de la Universidad Nueva Granada, el cual señala:

El presente artículo revisa conceptos básicos de pedagogía y modelos pedagógicos con el fin de reflexionar sobre la pertinencia del modelo constructivista en los cursos de ascenso de oficiales de la Armada Nacional, identificar su nivel de apropiación y presentar una propuesta para su fortalecimiento. [...]. La correcta integración de estos conceptos, a través de un diseño curricular apropiado es fundamental para generar la sinergia que garantice el éxito de cualquier proceso de enseńanza-aprendizaje. (p. 1)

En este trabajo también se realiza un valioso análisis del modelo en relación con las características de las Fuerzas y su contexto, como un elemento que se debe considerar. Para este análisis el autor toma una idea de Julián de Zubiría (2008), quien afirma que somos parte del posmodernismo y de una sociedad del conocimiento que genera constantes retos a la pedagogía. Consecuentemente, Medina (2017) reconoce que esto conlleva desafíos a la academia, entre los cuales incluye el desarrollo de mejores procesos de análisis y abstracción, leer comprensivamente, garantizar un entendimiento básico del mundo, formar hombres e instituciones flexibles, despertar el interés por el conocimiento y promover el respeto por las diferencias. Finalmente, aunque es interesante la manera como el artículo relaciona esta perspectiva con la profesión militar y sus cambios en el mundo actual, no hace referencia a las ciencias militares, de modo que se pueda hallar un engranaje epistemológico entre estas y las ciencias de la educación. 
En tercer lugar, el artículo de reflexión resultado de investigación de Edwin Ramírez Rubiano y Roberto Ramírez Bravo, "Educación en el Ejército Nacional de Colombia y el posconflicto", de la Universidad Mariana de San Juan de Pasto, fue desarrollado con soldados profesionales del Batallón de Instrucción y Entrenamiento. Específicamente, el documento sostiene:

El Ejército Nacional de Colombia debe poner en práctica programas y currículos académicos acordes con la realidad que vive el país, desde una perspectiva humanista, flexible y capaz de educar a líderes con vocación de servicio; para lo cual maestros e instructores deben repensar el sentido y la función de la enseñanza actual y, considerar las grandes transformaciones de la humanidad; deben generar cambios de pensamiento profundo en los soldados, de manera que se privilegie la creatividad, el análisis, la discusión y la capacidad para la toma de decisiones acertadas; la templanza, la argumentación y el conocimiento de sí mismo para enfrentar problemas y situaciones cotidianas. (p. 21)

Además, entre otros aspectos, el artículo promueve la transformación y proyección de la educación militar del soldado del futuro, como hombre multidimensional; propone elementos teóricos que fundamentan la educación militar como centro del mejoramiento, del crecimiento y de la transformación institucional; destaca procesos que contrarrestan los actos violatorios de los Derechos Humanos y el Derecho Internacional Humanitario, y, en general, insiste en mejorar las características intelectuales, pedagógicas y didácticas del docente. En el marco normativo descrito, en el documento se entiende por educación militar para el posconflicto el proceso evolutivo y necesario que transforma los procesos de enseńanza-aprendizaje y la doctrina militar en función de lo humano, la convivencia pacífica y la paz.

En cuarto lugar, el artículo de reflexión resultado de investigación de Olga Esperanza Terreros (2012), titulado "Investigando un modelo pedagógico desde y para lo castrense. Modelo Holístico Castrense", de la Escuela de Suboficiales del Ejército Nacional de Colombia (Esufa), presenta un esquema general de propuesta cuyo propósito es crear un modelo pedagógico para la formación castrense, con la égida de "creer en lo nuestro" y a partir de las características que identifican a un sello profesional. Desde allí, la autora hace un planteamiento que coincide con lo que se propone en esta investigación: 
Modelos y teorías son innumerables que se puedan citar y “recitar". Sería así fácil acudir a una o varias de ellas y tratar de amoldarlas o encuadrarlas a las necesidades del momento educativo, aspecto que sería consignado teóricamente en los proyectos educativos de las Fuerzas Militares; pero que, seguramente, sería relegado, ya que difícilmente se aplicaría a la práctica de su diario vivir en la formación. La dicotomía en la aplicación estaría soportada en la falta de pertinencia y pertenencia de muchos modelos que consignados como pilares de la educación tienen respecto a nuestras prácticas educativas. Quiere decir lo anterior que cuando hablamos de modelo de formación para un proyecto educativo de una institución militar, no pueden ser olvidadas sus raíces e historia para encajarlo en teorías educativas. (Terreros, 2012, p. 3)

En quinto lugar, "Análisis de los factores que conducen a la integración de la comunidad académica militar y civil dentro de un ambiente educativo en instituciones militares", de los autores Telma Viviana Castellanos, Nora Patricia Lozano, Jairo Alberto Álvarez y Marlon Gómez (2015), de la Universidad Santo Tomás de Colombia, grupo Cemil (Centro de Educación Militar), aborda diversos aspectos de la integración entre la comunidad académica militar y la civil dentro de un ambiente educativo en instituciones militares en Bogotá. El estudio tiene como propósito que la educación se encamine hacia una cultura de paz, la cual identifica en tres áreas de estudio: convivencia, ambientes educativos y currículo, para lograr la trazabilidad en cada uno de los procesos pedagógicos, partiendo de un análisis situacional. Así, se orienta a elaborar una propuesta que integre los nuevos retos de la educación impartida dentro de los tres ejes mencionados.

En sexto lugar, en el artículo resultado de investigación de Jenifer Lorena Gómez, Liliana de Jesús Monroy y Cristian Alberto Bonilla (2019), de la Universidad Libre, titulado "Caracterización de los modelos pedagógicos y su pertinencia en una educación contable crítica", se identifican los elementos, actores e intereses presentes en los modelos pedagógicos más relevantes en la literatura académica, en contraste con lo que se ha aplicado en la educación contable, con el fin de fundamentar un modelo pedagógico acorde con una formación contable crítica, analítica, activa y propositiva.

Particularmente, el texto parte de los elementos pedagógicos y profesionales esenciales para conformar el modelo educativo, para lo cual analiza las teorías y los modelos pedagógicos a través de los autores más citados por los 
investigadores consultados. Así, describe las características de los procesos de aprendizaje desde distintas ciencias sociales y, específicamente en el ámbito de la educación contable, se revisan artículos, libros y tesis que abordan las necesidades sociales del ejercicio profesional contable. Los autores concluyen que los modelos pedagógicos que podrían tener un mayor impacto en la generación de contadores críticos, analíticos, proactivos y propositivos son aquellos que otorgan un rol principal al estudiante y se enfocan en la formación de individuos que contribuyan al desarrollo social y económico de su entorno.

Finalmente, en sexto lugar, F. Vázquez (2018), en el artículo de reflexión "El proceso de modernización del Ejército ecuatoriano", realizado por la Universidad de las Fuerzas Armadas de Ecuador, se centra en la formación dual e integra aspectos de diferentes modelos pedagógicos observados desde la perspectiva de diversos autores, entre ellos Zubiría, Flórez, Díaz y Porlán. De esta manera, establece puntos relevantes que permiten constituir acuerdos entre ellos y analiza las discrepancias, por ejemplo la función que el docente ejerce en el aula de clase, entre otras. Asimismo, enmarca el constructivismo como modelo pedagógico principal, pero no establece los vínculos con el conductismo.

Este recorrido analítico por las investigaciones disponibles corrobora la necesidad de investigar los rasgos de la pedagogía que caracteriza la educación militar desde la conexión histórica y epistémica de estos conocimientos, de tal manera que desde allí sea posible hallar los fundamentos de la formación dual propia de la profesión militar. Es decir, reflexionar sobre las características pedagógicas que definen esta formación e indagar la relación que existe entre las ideas pedagógicas a lo largo del tiempo, con el fin de encontrar las conexiones histórico-genéticas que son válidas en este contexto.

Este es el camino y el supuesto que sigue esta investigación: estudiar las ideas pedagógicas del siglo XX en su origen y así identificar los aspectos comunes que comparten el constructivismo y el conductismo pedagógicos. Para dilucidar esta relación, se toman como conceptos articuladores la reflexividad y el eclecticismo crítico reflexivo, desde los cuales se reconocen los siguientes momentos lógicos y metodológicos: las conexiones de origen, la validez de estas ideas en su contexto y la actualidad y comunión con las ciencias militares 
y la profesión militar. A continuación, se precisan los términos epistemología e ideas pedagógicas desde la perspectiva de esta investigación.

\section{Epistemología e ideas pedagógicas}

\section{Epistemología}

La epistemología se refiere a aquella parte de la filosofía que se dedica a pensar sobre el conocimiento y sus procesos, a lo que también se le denomina gnoseología. Su estudio responde a la generación, validez y valor del conocimiento, a la comprensión de su generador, el ser humano, así como a las diferentes interpretaciones y enfoques de dicha comprensión que son necesarios para investigar y solucionar problemas mediante las teorías, los conceptos y los métodos. En este sentido, la epistemología se puede entender como la toma de conciencia acerca del proceso de crear o justificar conocimiento, lo cual significa que toda investigación científico-tecnológica pasa por la epistemología general y particular del conocimiento específico que se estudia.

Además, al estar en la base de todo conocimiento científico, por ser los lentes con que se observa, interpreta, explica, aplica y transforma el conocimiento, la epistemología permite llegar a las premisas, relaciones y esencias de los fenómenos que se investigan. Si no se asume una posición sobre el conocimiento que se emplea para investigar, es imposible comprender una realidad dada ni mucho menos proponer soluciones; es una situación similar a hallarse en un contexto impreciso y confuso. Por esta razón es tan necesario determinar el marco de referencia epistémica de una hipótesis o una tesis, pues esto permite identificar su orientación.

Este "conocimiento sobre el conocimiento" tiene diferentes niveles: de carácter general y particular, referidos a la ciencia de que se trate. Específicamente, la fundamentación epistémica de esta investigación está en el marco del conocimiento pedagógico, el cual permite explorar la relación histórico-genética que existe entre las dos corrientes de ideas pedagógicas que se han mencionado: el conductismo y el constructivismo, aparentemente opuestas en su práctica, pero entre las cuales hay un continuum y una identidad. La búsqueda de este continuum hace posible establecer las diferencias y las semejanzas o aspectos 
comunes, con el objetivo de eliminar la exclusión y el rechazo entre ambas y poder ver con claridad su comunicación en la práctica pedagógica, particularmente en las ciencias y profesión militares. Sentado esto, es más comprensible el porqué de esta investigación, así como la posición epistémica que se sigue — declarada en el marco teórico— y el camino metodológico elegido.

\section{Perspectiva, enfoque y tendencia}

Consecuentemente, algunos términos con los cuales se identifican y narran las posiciones epistemológicas que se consideran en las ciencias sociales son: perspectiva, enfoque y tendencia, los cuales son utilizados en esta investigación.

La perspectiva, que tiene su naturaleza en el arte y la arquitectura, es el punto de vista, la mirada desde la cual se analiza o considera un asunto. También se considera el conjunto de características que desde un punto determinado se presentan a la vista del espectador, especialmente cuando están lejanas; visión considerada en principio más ajustada a la realidad, que viene favorecida por la observación espacial o temporal de cualquier hecho o fenómeno. Tanto para el arte como para la arquitectura, la perspectiva expresa subjetividad desde la interpretación, aunque contradictoriamente al ser un resultado de los aprendizajes, se establece como paradigma de la comprensión de los sujetos. Entre los destacados filósofos del siglo XX que la fundamentan están Ortega y Gasset y Nietzsche, reconocidos críticos del dogmatismo y el realismo que dan sustento al pragmatismo, el pluralismo, el relativismo, el escepticismo y el nihilismo, hoy llamado posmodernismo, que niega los hechos, la verdad y la capacidad del ser humano de conocer esencias (De Santiago, 2001).

Por su parte, el enfoque, según Mario Bunge, es un cuerpo de conocimiento preexistente, junto con una interpretación de problemas, un conjunto de objetivos y una colección de métodos, un arquetipo que marca una conducción con base en una manera de ver las cosas o las ideas, y en consecuencia también de tratar los problemas relativos a ellas (Bunge, 2002). Para este epistemólogo y metodólogo de la ciencia, existen ocho enfoques para hacer investigación: (1) vulgar, (2) empírico, (3) doctrinario, (4) humanístico, (5) matemático, (6) de la ciencia básica, (7) de la ciencia aplicada y (8) tecnológico. 
A manera de ilustración, el término enfoque también es definido por investigadores de la gestión educativa: según Alvarado (1999), este se refiere a la forma de entender, analizar o estudiar algún fenómeno o hecho social. Además de señalar que un enfoque puede llegar a constituirse en escuela si se universaliza y tiene seguidores, Oyarce (1999) diferencia tres categorías: el enfoque burocrático, el sistémico y el gerencial. Asimismo, para Sander (1996), los enfoques están basados en descubrir, dirigir, proyectar y comprender los puntos esenciales de un asunto o problema educativo para tratarlo acertadamente de manera flexible, ya que estos se pueden replantear para dar origen a modelos y corrientes pedagógicas. Particularmente, este autor presenta cinco enfoques conceptuales y analíticos diferentes sobre la gestión educativa: jurídico, tecnocrático, desarrollista y sociológico, los cuales describe desde un punto de vista histórico.

Finalmente, por tendencia se entiende el patrón de comportamiento que tienen los elementos de un entorno particular durante un período. Así, es entendida como el curso y las orientaciones que toma un fenómeno o problemática, los cuales están determinados por el contexto y las concepciones que se tenga sobre este.

Ahora bien, el enfoque de esta investigación es la integración del conocimiento y la integralidad del ser humano como bio-psico-social-cultural, que en la pedagogía pone al ser humano en el centro de la enseñanza y el aprendizaje. Precisamente, este es el enfoque que se analiza como tendencia histórica en las ideas pedagógicas de algunos representantes del siglo pasado, para mostrar el continuum de comunidad de ideas y propuestas educativas con la actualidad.

\section{Ideas pedagógicas}

Son diversas las acepciones que se tienen sobre el término idea. Dependiendo de su uso, puede ser la ocurrencia, el supuesto o hipótesis, una propuesta creativa, pero en todos los casos es una proposición desde un conocimiento no conceptual aún que se hace sobre una cuestión determinada, que en este caso es la educación. La idea es un punto inicial para conformar posteriormente una propuesta fundamentada. 
Particularmente, la noción de ideas pedagógicas se utiliza tanto para estudiar los puntos de partida de los cambios pedagógicos, como en el debate que existe sobre el contenido, conceptualización y carácter científico de la pedagogía, que no es objeto de esta reflexión. Considerando lo anterior, se trata del pensamiento pedagógico que surge desde la reflexión sobre la práctica de la educación, como necesidad de sistematizarla y organizarla en función de determinados fines. Las ideas pedagógicas son constituyentes del conocimiento pedagógico y educacional, que dependen de los diferentes contextos históricos. Estas ideas conforman los cambios que tienen lugar en respuesta a las necesidades sociales, el avance cultural y los nuevos conocimientos científicos.

Como se esbozó en la primera parte del capítulo, la educación es un proceso social e histórico por medio del cual tiene lugar la transmisión, socialización, apropiación y desarrollo del acervo cultural de la humanidad en sus diversos contextos. Sus contenidos son cada vez más complejos e interdisciplinarios, y también menos duraderos, pues el avance de la ciencia y la tecnología (tecnociencia) produce cambios de manera acelerada en la sociedad, y por tanto en la educación, de tal manera que se hace cada vez más necesaria la reflexión epistemológica, metodológica, axiológica y disciplinar de las ciencias en la educación, para solucionar problemas actuales desde nuevas maneras de pensar y actuar, y generar cultura (Arana, 2018).

Otra razón por la cual se utiliza el término ideas pedagógicas es para no asumir un compromiso con su carácter científico ni con el enfoque interpretativo, sino que se conciben como discursos pedagógicos llevados a la práctica.

La incidencia que han tenido los conocimientos científicos en la educación a lo largo de su historia se ha expresado en ideas, enfoques, corrientes y modelos pedagógicos, los cuales han generado diversas polémicas que aún perduran. Estos conocimientos, que han emanado de la biología, la medicina y la psicología, son conexos a la comprensión del ser humano y sus procesos de conocimiento y aprendizaje. Además, son conducentes a pensar la enseñanza, sus medios, formas y métodos, así como los contenidos curriculares y ambientes culturales que brinda la institución educativa (Arana, 2018).

Hasta aquí se presentaron las razones que condujeron a la investigación y los puntos de vista de los investigadores para realizarla. A continuación se hace referencia a la metodología. 


\section{Metodología}

El paradigma de investigación fue cualitativo-interpretativo. Se trata de una investigación de análisis documental que tiene como objeto de pesquisa lo teórico, lo cual se aborda desde una mirada histórica y actual. En este sentido, este trabajo supone un acercamiento a los conocimientos, cosas o sujetos desde el plano reflexivo de las cualidades, de manera que su estructura consiste en una descripción verbal y/o explicativa de un fenómeno o hecho determinado (Campbell \& Stanley, 1982).

Al tratarse de una investigación documental, fue indispensable seleccionar los documentos según el objeto de investigación y el problema. Una vez elegidos, se procedió a analizar el tema siguiendo la propuesta de Galeano (2004), quien señala que todos estos textos pueden ser "entrevistados" mediante las preguntas que guían la investigación, y que es posible "observarlos" con la misma intensidad con la que se observa un evento o un hecho social. En consecuencia, la lectura de documentos es una mezcla de entrevista y observación al documento (2004).

Por lo tanto, el método que se aplica es el análisis teórico e hipotético deductivo. La técnica de análisis de contenido permitió la observación y el análisis de los documentos, para comprender su estructura interna y los contextos en los cuales se produce la información.

Finalmente, los documentos analizados fueron de carácter intertextual-extensivo, es decir, relacionados entre sí a través del objeto de estudio: los enfoques epistémicos-pedagógicos en los modelos educativos de la formación militar; documentos de investigaciones realizadas sobre el modelo pedagógico de formación en instituciones militares de Colombia; de políticas educativas en las Fuerzas Militares de Colombia; escritos sobre pedagogos destacados del siglo XX; investigaciones sobre el conductismo y el constructivismo pedagógicos, así como los conceptos de reflexividad pedagógica, eclecticismo reflexivo, constructivismo, conductismo, modelo pedagógico, formación militar, entre otros. 


\section{Referencias}

Abbagnano, N., \& Visalberghi, A. (1964). Historia de la pedagogía. Fondo de Cultura Económica.

Acevedo, E. B. (1995). La formación humana integral: Una aproximación entre las humanidades y la ciencia. Organización de Estados Iberoamericanos. http://bit.ly/2x9pbp7

Acosta Arévalo, C., \& Ibarra, V. (2018). El redimensionamiento curricular por competencias en la formación del profesional en ciencias militares. En M. Arana, \& V. Ibarra (Eds.), Educación cientifica y cultura investigativa en ciencias militares (2. a ed.; pp. 81-122). Sello Editorial ESMIC.

Acosta Arévalo, C., Arana Ercilla, M., Mendoza Gómez, M., Valencia García, F., \& Muñoz Niño, J. A. (2012). La evaluación de competencias transversales de lectoescritura en el área de investigación para la formación del profesional de ciencias militares. Revista Cientifica General José María Córdova, 10(10), 259-285. https://doi. org/10.21830/19006586.237

Alarcón, L. (2014). Tendencias y desafíos de la historia de la educación: Nuevas perspectivas sobre una disciplina en construcción. Atenas Revista Cientifico Pedagógica, 1(25), 1-26. https://www.redalyc.org/pdf/4780/478047201001.pdf

Alvarado, O. (1999). Gestión educativa: enfoques y procesos. Universidad de Lima.

Andrade, G. (2006). Fundamentación y lineamientos para el trabajo valorativo [Documento de trabajo]. Instituto Alberto Merani.

Arana, M. (2018a). Prefacio. En M. Arana \& V. Ibarra (Eds.), Educación cientifica y cultura investigativa en ciencias militares (2. ${ }^{ } \mathrm{ed}$.; pp. 13-22) Sello Editorial ESMIC.

Arana, M. (2018b). Un acercamiento a la ciencia como unidad del conocimiento. En M. Arana, \& V. Ibarra (Eds.), Educación cientifica y cultura investigativa en ciencias mili-

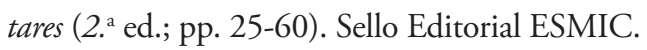

Arana, M., Acosta, C., Ibarra, V., \& Reyes, D. (2019). Hallazgos y desafíos de la tutoría del trabajo de grado desde un estudio de caso: Punto de partida para proponer competencias del tutor. En M. Arana, \& V. Ibarra (Eds.), Ideas y experiencias pedagógicas: Investigación formativa y la tutoría de trabajo de grado en la educación superior (pp. 72-115). Sello Editorial ESMIC.

Arana, M., Garzón, L., López, E., Clavijo, A., \& Ramírez, J. (2016). Una mirada a la gestión de la educación en Colombia para pensar la cultura de la investigación. 
En M. Arana, \& V. Ibarra (Eds.), Cultura de la investigación y gestión educativa: Experiencias desde tres universidades (pp. 93-120). Sello Editorial ESMIC.

Aubert, A., Flecha, A., García, C., Flecha, R., \& Racionero, S. (2008). El aprendizaje dialógico en la sociedad de la información. Hipatia Editorial.

Bachelard, G. (1987). La formación del espíritu cientifico. Siglo XXI.

Badiou, A. (2007). Manifiesto por la filosofía. Nueva Visión.

Barberousse, P. (2008) Fundamentos teóricos del pensamiento complejo de Edgar Morín. Revista Educare, 12(2), 95-113. https://www.redalyc.org/pdf/1941/194114586009.pdf

Bedoya, I. (2018). Epistemología y pedagogía: Paradigmas de la pedagogía en la educación (7. ${ }^{\mathrm{a}}$ ed.). ECOE.

Bruer, J. T. (2016). Neuroeducación: Un panorama desde el puente. Revista Propuesta Educativa, 46(2), 14-25. http://propuestaeducativa.flacso.org.ar/wp-content/ uploads/2019/11/REVISTA46-dossier-bruer.pdf

Bunge, M., \& Ardila, R. (2002). Filosofía de la psicología (2. a ed.). Siglo XXI.

Carbonell, J. (2000). La memoria: Arma de futuro. En Pedagogías del siglo XX [Cuadernos de Pedagogía. Especial 25 años]. Editorial Ciss Praxis.

Castañeda, E. (1998). Enfoque sistémico del diseño curricular: Sintesis metodológica [Ponencia]. Conferencia sobre Diseño Curricular del II Taller IGLU-Caribe, Universidad Simón Bolívar, Venezuela.

Castellanos, T. V., Lozano, N. P., Gómez, M., \& Álvarez, J. A. (2015). Análisis de los factores que conducen a la integración de la comunidad académica militar y civil dentro de un ambiente educativo en instituciones militares [Tesis de Maestría, Universidad de Santo Tomás]. Repositorio USTA. https://repository.usta.edu.co/handle/11634/588

Cerletti, A. (2008). La enseñanza de la filosofía como problema filosófico. Libros del Zorzal.

Chevallard, Y. (1991). La transposición didáctica: Del saber sabio al saber enseñado. Aique.

Chevallard, Y. (1997). La transposición didáctica: Del saber sabio al saber enseñado. Aique.

Chevallard, Y. (1998). La transposición didáctica: Del saber sabio al saber enseñado. Aique.

Coffey A., \& Atkinson, P. (2005). Encontrar el sentido a los datos cualitativos: Estrategias complementarias de investigación. Universidad de Alicante. https://www.fceia.unr.edu. ar/geii/maestria/2014/DraSanjurjo/8mas/Amanda\%20Coffey,\%20Encontar\%20el\%20 sentido\%20a\%20los\%20datos\%20cualitativos.pdf

Coll, C., Martín, E., Mauri, T., Miras, M., Onrubia, J., Sole I., \& Zabala, A. (1996). El constructivismo en el aula, Graó.

Comando de Educación y Doctrina [CEDOC]. (2018). PEI: Documentos rectores. Institución Universitaria Comando de Educación y Doctrina. 
Covarrubias, A. (2001). La dialéctica de Aristóteles: Un modelo para la argumentación retórica. Seminarios de Filosofía, 14-15, 45-63. https://repositorio.uc.cl/xmlui/bitstream/ handle/11534/9948/000338162.pdf

Cronbach, L. J. (1982). Prudent aspirations for social inquiry. En W. Kruskal (Ed.), The future of the social sciences. University of Chicago Press. https://es.calameo.com/ $\mathrm{read} / 000834724 \mathrm{e} 795 \mathrm{c} 2 \mathrm{bc} 0172$

De Conti, M. (2018). Teoría del conocimiento pedagógico. Revista Pedagogía y Saberes, 49, 177-188. https://doi.org/10.17227/pys.num49-8179

De Santiago, L. E. (2001). Las ilusiones del conocimiento: Perspectivismo e interpretación. Universalismos, Relativismo, Pluralismos. Thématha, 27, 23-139. https://idus. us.es/bitstream/handle/11441/27578/file_1.pdf?sequence=1

De Zubiría, J. (2001). Teorías contemporáneas de la inteligencia y la excepcionalidad. Magisterio.

De Zubiría, J. (2004). Una propuesta para la formación valorativa: La experiencia del Instituto Alberto Merani. Ediciones del Instituto Alberto Merani.

De Zubiría, J. (2006). Los modelos pedagógicos: Hacia una pedagogía dialogante. Magisterio.

De Zubiría, J. (2008). Los modelos pedagógicos: Hacia una pedagogía dialogante (3. a ed.). Aula Abierta.

Delval, J. (2002). Desarrollo humano (1. a ed.). Siglo XXI.

Domingo, A. (2008). La práctica reflexiva en la formación inicial de maestros/as: Evaluación de un modelo [Tesis de doctorado, Universidad de Barcelona]. https://practicareflexiva. pro/wp-content/uploads/2011/04/Tesis_Angels_Domingo.pdf

Domingo, A. (s. f.). Reseña del libro El profesional reflexivo, de D. A. Shön. https://practicareflexiva.pro/wp-content/uploads/2019/03/D.SCHON_FUNDAMENTOS.pdf

Ejército Nacional de Colombia. (2017a). Manual fundamental de Referencia del Ejército Nacional de Colombia (MFRE) 3-0: Operaciones (1. a ed.). Imprenta Militar del Ejército. https://www.dicoe.mil.co/recurso_user/doc_contenido_pagina_ web/800130633_4/458776/mfre_3_0_operaciones.pdf

Ejército Nacional de Colombia. (2017b). Manual fundamental del Ejército Nacional MFE 1.0: El Ejército (1.a ed.). Imprenta Militar del Ejército. https://www.dicoe.mil.co/ recurso_user/doc_contenido_pagina_web/800130633_4/458749/mfe_1.0_el_ejercito.pdf

Escobar, J. (2000). Bioética: origen y tendencias. Revista Facultad de Medicina, 48(4), 219-223.

Escobar, J. (Dir.). (1999). Temas de bioética en Colombia (vol. 8). Universidad de El Bosque. Escolano, A. (2000). Las culturas escolares del siglo XX: Encuentros y desencuentros. Revista de Educación, (número extraordinario, 1), 201-218. https://redined.mecd.gob. es/xmlui/bitstream/handle/11162/73415/008200230158.pdf?sequence $=1$ 
Escuela Militar de Cadetes “General José María Córdova” [ESMIC]. (2017). Proyecto Educativo Institucional (Acuerdo N. ${ }^{\circ}$ 008). ESMIC.

Escuela Militar de Cadetes “General José María Córdova” [ESMIC]. (2018). Proyecto Educativo del Programa Profesional en Ciencias Militares. ESMIC.

Escuela Militar de Cadetes “General José María Córdova” [ESMIC]. (2019). Proyecto Educativo del Programa de Profesional en Ciencias Militares. Colombia. ESMIC.

Esnier, E. Y., \& Vallance, E. (1974). Conflicting conceptions of curriculum. http://mehrmohammadi.ir/wp-content/uploads/2020/01/Conflicting-Conceptions-of-Curr-Elliot-W.Eisner.pdf

Espina, M. (2004). Humanismo, totalidad y complejidad: El giro epistemológico en el pensamiento social y la conceptualización del desarrollo. En La participación: Diálogo $y$ debate en el contexto cubano (pp. 13-39). Centro de Investigación y Desarrollo de la Cultura Cubana "Juan Marinello".

Fernández, S., \& Flores, M. (2013). Tutors' and students' views of tutoring: A study in higher education. En M. A. Flores, A. A. Carvalho, F. I. Ferreira, \& M. T. Vilaça, Back to the future: Legacies, continuities and changes in educational policy, practice and research (pp. 277-295). Sense Publishers.

Freire, P. (1970). Pedagogía del oprimido. Siglo: XXI.

Freire, P. (2002). Pedagogía de la esperanza (5. ${ }^{\mathrm{a}}$ ed.). Siglo XXI.

Freydell, G. (2020). Narrativa del cuerpo vivido para procesos deliberativos en bioética: Una metodología de intervención-formación situada en el espectador del acoso escolar [Tesis doctoral, Universidad Militar Nueva Ganada]. Repositorio UMNG. https://repository.unimilitar.edu.co/handle/10654/35995

Fuerza Aérea Colombiana. (2017). El modelo pedagógico del sistema educativo de la Fuerza Aérea Colombiana. Publicaciones Fuerzas Militares. https://d2r89ls1uje5rg.cloudfront. net/sites/default/files/modelo_pedagogico_2017.pdf

Galeano, M. E. (2004). Estrategias de investigación social cualitativa: El giro de la mirada. La Carreta.

García, E. (2008). Neuropsicología y educación: De las neuronas espejo a la teoría de la mente. Revista de Psicología y Educación, 1(3), 69-90. https://eprints.ucm.es/id/ eprint/9972/1/Revista_Psicologia_y_Educacion.pdf

Gardner, H. (1993). La mente escolarizada: Cómo piensan los niños y cómo debería enseñarles las escuelas. Paidós.

Gell-Mann, M. (1995). Aventuras de lo simple a lo complejo. Tusquets.

Gimeno Sacristán, J. (2007). El curriculum: Una reflexión sobre la práctica. Morata.

Gómez, J. L., Gómez, L. Monroy, \& C. A. Bonilla. (2019). Caracterización de los modelos pedagógicos y su pertinencia en una educación contable crítica. Entramado, 15(1), 164-189. https://doi.org/10.18041/1900-3803/entramado.1.5428 
González, A. (2004). Aportaciones de la psicología conductual a la educación. Revista Electrónica Sinéctica, 25, 15-22.

González, T. (2009) Flexibilidad y reflexividad en el arte de la investigación cualitativa. Index de Enfermería, 18(2), 121-125. https://scielo.isciii.es/scielo.php?script=sci_arttext\&pid=S1132-12962009000200012

Grisales, L. M., \& González, E. M. (2009). El saber sabio y el saber enseñado: Un problema para la didáctica universitaria. Revista Educación y Educadores, 12(2), 77-86. https:// www.redalyc.org/articulo.oa?id=83412219005

Gros, B. (2001). Burrhus Frederic Skinner y la tecnología de la enseñanza. En J. Trilla Bernet (Coord.), El legado pedagógico del siglo XX para la escuela del siglo XXI (pp. 229-248). Graó. https://campus.fundec.org.ar/admin/archivos/Trilla\%20J-\%20El\%20 Legado\%20Pedagogico\%20Del\%20Siglo\%20XX\%20Para\%20La\%20Escuela\%20Del\%20 Siglo\%20XXI.pdf

Gutiérrez, A. (2013). Bioética y responsabilidad social corporativa: Consideración para la formación integral universitaria. Quipukamayoc, 21(39), 19-27. https://oi. org/10.15381/quipu.v21i39.6267

Habermas, J. (1987). Teoría de la acción comunicativa (t. 1 y 2). Taurus.

Huerta, M. (2015). La estrategia en el aprendizaje (1. a ed.). Magisterio.

Ley 30 de 1992. "Por la cual se organiza el servicio público de la Educación Superior". Congreso de la República de Colombia. Diario Oficial, N.o 40.700. http://www. secretariasenado.gov.co/senado/basedoc/ley_0030_1992.html

Lipina, S. (2016). Actualizaciones en neurociencia educacional. Propuesta Educativa, 46(2), 6-13. https://www.redalyc.org/pdf/4030/403049783002.pdf

Martín, E. Y., \& Martínez, F. (2009). Avances y desafíos en la evaluación educativa. Organización de Estados Iberoamericanos. http://www.redage.org/sites/default/files/ adjuntos/EVAL.pdf

Martínez Bonafé, J. (1994). Los olvidados: Memoria de una pedagogía divergente. Cuadernos de Pedagogía, 230, 58-65. https://dialnet.unirioja.es/servlet/articulo?codigo $=35850$

Martínez, J. F. (2004). El problema de la reflexividad de las predicciones en Economía: Las perspectivas de Karl Popper y George Soros. En A. Vicente, P. de la Fuente, C. Corredor, \& J. A. Marcos. (Eds.). Actas del IV Congreso de la Sociedad de Lógica, Metodología y Filosofía de la Ciencia en España (pp. 192-196). Sociedad de Lógica, Metodología y Filosofía de la Ciencia en España.

Martínez, M. (2009). Dimensiones básicas de un desarrollo humano integral. Polis, 8(23), 119-138. https://www.redalyc.org/pdf/305/30511379006.pdf 
Mead, G. (1982). Espiritu, persona y sociedad desde el punto de vista del conductismo social. Paidós.

Medina, N. A. (2017). Pertinencia del modelo pedagógico constructivista en los cursos de ascenso de oficiales de la Armada Nacional y propuesta para su fortalecimiento [Trabajo de especialización, Universidad Militar Nueva Granada]. Repositorio UMNG. https://repository.unimilitar.edu.co/handle/10654/16102

Mendoza, M. (2018). La lectoescritura: Una competencia para el fortalecimiento de la investigación formativa fundamental en la profesión militar. En M. Arana, \& V. Ibarra (Eds.), Educación cientifica y cultura investigativa en Ciencias Militares (2. ${ }^{\text {a }}$ ed.; pp. 253-284). Sello Editorial ESMIC. https://librosesmic.com/index.php/editorial/ catalog/view/58/42/723

Merani, A. (1977). Naturaleza humana y educación. Grijalbo.

Ministerio de Defensa Nacional. (2008). Plan Estratégico 2007-2019. Imprenta y Publicaciones de las Fuerzas Militares https://www.mindefensa.gov.co/irj/go/km/docs/ Mindefensa/Documentos/descargas/estrategia_planeacion/desa_capital/Pagina/PESE_ FINAL.pdf

Ministerio de Defensa Nacional. (2010). SEFA Lineamientos curriculares de las Fuerzas Militares. Imprenta y Publicaciones de las Fuerzas Militares. https://www.dicoe.mil. co/recurso_user/doc_contenido_pagina_web/800130633_4/429594/2._sistema_educativo_de_las_fuerzas_armadas_sefa..pdf

Ministerio de Defensa Nacional. (2021). Política de educación para la Fuerza Pública (PEFuP) 2021-2026: Hacia una educación inteligente, estratégica y de calidad. https:// policia.edu.co/wp-content/uploads/2021/09/Poli\%CC\%81tica-de-Educacio\%CC\%81npara-la-Fuerza-Pu\%CC\%81blica-2021-2026-Versio\%CC\%81n-Final.pdf

Mitchan, C. (1989). ¿Qué es la filosofía de la tecnología? Anthropos.

Monereo, C., Castello, M., Clariana, M., Palma, M., \& Pérez, M. (2001). Estrategias de enseñanza y aprendizaje. Graó.

Mora, F. (2008). El cientifico curioso: La ciencia del cerebro en el día a día. Temas de Hoy.

Morín, E. (1994). Prólogo. En Introducción al pensamiento complejo. Gedisa.

Morín, E. (1998). El pensamiento complejo. Gedisa.

Morin, E. (2011). Los siete saberes necesarios para la educación del futuro (2. ${ }^{\mathrm{a}} \mathrm{ed}$.). Magisterio.

Narciandi, J. C., \& Martín, G. (2009). La historia como maestra para la investigación en imitación animal. Revista de Historia de la Psicología, 30(2-3), 187-194.

Novoa, F. (1997). La investigación histórico educativa: Tendencias actuales. Ronsel.

Olivé, L. (2007). La ciencia y la tecnología en la sociedad del conocimiento: Ética, política y filosofía. Fondo de Cultura Económica. 
Orellana, O. (2003). Enseñanza aprendizaje y la medición constructivista. San Marcos.

Organización de las Naciones Unidas para la Educación, la Ciencia y la Cultura [UNESCO]. (2007). Educación de calidad para todos: Un asunto de Derechos Humanos. UNESCO.

Organización de las Naciones Unidas para la Educación, la Ciencia y la Cultura [UNESCO]. (2015). 70a Asamblea General de la Organización de Naciones Unidas. UNESCO.

Organización de las Naciones Unidas para la Educación, la Ciencia y la Cultura [UNESCO]. (2005). Declaración universal sobre bioética y Derechos Humanos. https:/www.unisabana.edu.co/fileadmin/Archivos_de_usuario/Documentos/Documentos_ Investigacion/Docs_Comite_Etica/UNESCO_Bioetica_y_Derechos_Humanos_2005_ unisabana.pdf

Ortega y Gasset, J. (1995). Ideas y creencias. Alianza.

Perilla, J. (2018). Hacia un constructivismo ecléctico desde el misreading. En J. Perilla (Comp.), Constructivismo ecléctico desde la reflexión curricular (pp. 13-42). Universidad Sergio Arboleda y Alcaldía Mayor de Bogotá.

Perilla, J. (2019). Los valores profesionales como enfoque educativo ecléctico en el diseño curricular. En M. Arana, \& V. Ibarra, Metodología para la evaluación de los valores profesionales (pp. 22-37). Sello Editorial ESMIC. https://doi. org/10.21830/9789585287846.01

Posner, R. (2005). Análisis del currículo. McGraw-Hill.

Potter, V. (1971). Bioethics: Bridge to the future. Prentice Hall.

Potter, V. R. (1988). Global bioethics: Building on the Leopold legacy. Michigan State University Press.

Quintanilla, M. A. (1999). Tecnología: Un enfoque filosófico. Fondo de Cultura Económica.

Ramírez, E. Y., \& Ramírez, R. (2015). Educación en el Ejército Nacional de Colombia y el posconflicto. Criterios, 22(1), 199-214.

Rizzolatti, G. (2005). The Mirror Neuron System and imitation. En S. Hurley, \& N. Chater (Eds.), Perspectives on imitation: From neuroscience to social science (vol. 1., Mechanisms of imitation and imitation in animals; pp. 55-76). MIT Press.

Ruiz, L. (2007). Formación integral: Desarrollo intelectual, emocional, social y ético de los estudiantes. Revista Universidad de Sonora, 19, 11-13. http://www.revistauniversidad. uson.mx/revistas/19-19articulo\%204.pdf

Salazar, E. (2011). Bioética: ¿Ciencia o disciplina? Investigación en Enfermería: Imagen $Y$ Desarrollo, 5(1), 64-77. https://revistas.javeriana.edu.co/index.php/imagenydesarrollo/ article/view/1553 
Sander, B. (1996). Gestión educativa en América Latina: Construcción y reconstrucción. Troquel Educación.

Schaeffer, J-M. (2009). El fin de la excepcionalidad humana. Fondo de Cultura Económica.

Schön, D. A. (1998). El profesional reflexivo: Cómo piensan los profesionales cuando actúan. Paidós. (Trabajo original publicado en 1983, en Nueva York).

Segura Moreno, C. (2006). Aprender a aprender: Claves para su enseñanza [versión electrónica]. Educación y Educadores, 5(0). http://educacionyeducadores.unisabana.edu.co/ index.php/eye/article/view/562/708

Skinner, B. F. (1979). Contingencias de reforzamiento: Un análisis teórico [E. Galindo Cota, Trad.). Trillas. (Trabajo original publicado en 1969).

Skinner, B. F. (1986). Ciencia y conducta humana (M. J. Gallofre, Trad.). Martínex Roca (Trabajo original publicado en 1953).

Snow, C. P. (1977). Las dos culturas y un segundo enfoque. Alianza.

Soros, G. (2014). Fallibility, reflexivity, and the Human Uncertainty. Principle. Journal of Economic Methodology, 20(4), 309-329. https://doi.org/10.1080/1350 178X.2013.859415

Suárez, M. (2000). Las corrientes pedagógicas contemporáneas y sus implicaciones en las tareas del docente y en el desarrollo curricular. Acciones Pedagógicas, 9(1), 42-51. http://www.saber.ula.ve/bitstream/handle/123456789/17010/art6_12v9.pdf;jsessionid=C68117BC46EA9FB072D90F45C265C3BF?sequence=1

Suárez, R. (1987). La educación, su filosofía, su psicología, su método. Trillas.

Terreros, O. E. (2012). Investigando un modelo pedagógico desde y para lo castrense 2012. TecnoESUFA: Revista de Tecnología Aeronáutica, 18, 8-16. https://publicacionesfac.com/index.php/TecnoESUFA/article/view/373/493

Tezano, A. (2016). Formación de maestros: Los conceptos articuladores del diseño curricular. Revista Educación y Cultura, 113, 8-18. https://mediateca.ctera.org.ar/files/origi-

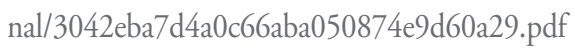

Thines G., \& Lempereur, A. (1975). Dictionnaire general des Sciences Humaines. Cátedra.

Tobón, S. (2013). Formación integral y competencias: Pensamiento complejo, currículo, didáctica y evaluación ( $4 .^{\mathrm{a}}$ ed.). ECOE.

Vázquez, F. (2018). La educación militar en el proceso de modernización del Ejército Ecuatoriano. Universidad de las Fuerzas Armadas de Ecuador. https://www.researchgate.net/publication/323780293

Vázquez, M. A. (2017). La reflexividad y su relación con el desarrollo de las habilidades profesionales de la práctica docente. www.conisen.mxımemoriasımemorias, C180117-H162.docx.pdf 
Vera, R., \& Palma, S. (2017). Enseñar a aprender: Pedagogía basada en la reflexividad. http://ipaulofreire.cl/wp-content/uploads/2019/04/Libro-Pedagog\%C3\%ADaVersi\%C3\%B3n-Agosto-2017.pdf

Vygotsky, L. (1987). El desarrollo de los procesos psicológicos superiores. Austral.

Wasserman, M. (2018a). Algunas “verdades" se establecen y son aceptadas por la gente de forma acrítica. En Cómo tener siempre la razón. Fondo de Cultura Económica.

Wasserman, M. (2018b). De progresista a reaccionario sin cambiar de ideas. En Cómo tener siempre la razón. Fondo de Cultura Económica.

Wells, G. (2001). Indagación dialógica: Hacia una teoría y una práctica sociocultural de la educación. Paidós.

Wilson, E. O. (1999). Consilience: La unidad del conocimiento. Galaxia Gutenberg.

Zemelman, H. (1998). Crítica, epistemología y educación. Revista de Tecnología Educativa, 13(2).

Zimmerman, M. (2013). Pedagogía ambiental para el planeta en emergencia (3. a ed.). ECOE.

Zuluaga, O., Vitarelli, M., Veiga, A., Schérer, R., Saldarriaga O., Sáenz, J., Runge P., A. K., Rifâ V., M., Quiceno Castrillón, H., Noguera R., C. E., Narodowski, M., Martínez Boom, A., Echeverri Sánchez, J. A., Caruso, M., \& Aguilar R., D. A. (2005). Foucault, la pedagogía y la educación: Pensar de otro modo. Universidad Pedagógica Nacional; Magisterio. 